\title{
Planejamento e Gerência no Enfoque Estratégico-Situacional de Carlos Matus
}

\section{Planning and Management in the Strategic-Situational Approach of Carlos Matus}

\section{Creuza da S. Azevedo'}

\section{AZEVEDO, C. da S. Planning and Management in the Strategic-Situational Approach of} Carlos Matus. Cad. Saude Públ., Rio de Janeiro, 8 (2): 129-133, abr/jun, 1992.

This study addresses conceptual aspects of planning and their relationship with management, as outlined in the strategic-situational approach of Carlos Matus.

Interest in the relationship between planning and management arises from reflection on theoretical works in the areas of planning (particularly health planning) and administration and management, each of which has evolved as a separate area of knowledge. Recently, however, there has been more explicit exchange of ideas and beginnings of dialogue between these two areas.

Contributions arising from Matus" strategic-situational approach indicate possible areas of articulation between the perspectives of these two schools.

In order to identify specific problems and concerns which link administration and planning, this study begins with a few brief considerations related to today's administrative impasses and perspectives, particularly in the public sector in Latin America.

In keeping with our objective, the central axis of the adudy is the concept of planning and management proposed by Matus, including the so-called "times for situational planning" emphasizing tactical-operational aspects, one approach to decision-making - a key question in management.

Keywords: Decision Making; Situation; Knowledge; Calculation; Action

\section{INTRODUÇÃO}

As preocupações mais recentes no campo da administração (Kliksberg, 1990) apontam, antes de tudo, para a necessidade de construção de um novo paradigma, já que as abordagens prescritivas das teorias tradicionais mostram-se inapropriadas frente aos desafios que se colocam na atualidade. No campo da administração pública, a ênfase na concepção apenas de modernização das estruturas organizacionais, ou seja, na mudança dos aspectos formais, não tem levado a mudanças substanciais no seu modo de funcionamento ou mesmo na efetividade das ações.

\footnotetext{
'Departamento de Administraçāo e Planejamento da Escola Nacional de Saúde Pública. Rua Leopoldo Bulhöes, 1480, Rio de Janeiro, RJ, 21041-210, Brasil.
}

Há uma crescente preocupação com a questão da mudança da máquina pública, no sentido de tomá-la não apenas eficiente, mas também eficaz e passivel de controle social. Incorporase, então, a compreensão do processo de mudança da máquina pública como mudança social e, para tal, a necessidade de um enfoque político e estratégico.

Nos enfoques tradicionais, a abordagem aos problemas gerenciais encontram-se fortemente marcados por características prescritivas, onde a realidade é um "deve ser".

A problemática acerca da construção de um novo paradigma abarca a compreensão da complexidade dos processos de mudança (resistências/conflitos), ressaltando as condiçōes de incerteza e mudanças constantes presentes no contexto ambiental e apontando o componente político-estratégico como essencial. A compre- 
ensão da gerência e do processo decisório está fortemente marcada pela valorização do componente estratégico, bem como pelo papel da inovação e criatividade, imprescindíveis ao atual cenário de incertezas e mudanças intensas. As organizações são compreendidas como arenas permanentes de negociação e conflito. $O$ componente técnico passa a ser um dos elementos do processo gerencial, que não se esgota na simples aplicação de instrumentos técnicos, strictu sensu.

O debate acerca da administração pública aponta para a integração necessária da esfera da política, do planejamento e da administração.

\section{A CONCEPÇÃO DE PLANEJAMENTO EM MATUS}

A concepção de planejamento presente na obra de Matus parte da articulação planejamento e governo. Pretende resgatar o planejamento como método de governo, como ferramenta útil, flexivel e eficaz para lidar com as necessidades da direção em cada lugar da administração pública. Governo, em Matus, se refere ao comando de um processo, não apenas do Estado, mas também de um ministério, sindicato ou unidade de saúde, por exemplo. Neste sentido, nos diz Matus (1985: 29), La planificación estrategica redefine $y$ identifica, en buenas cuentas, dirección con planificación, no hace una separación tajante entre ambas.

A tomada de decisões é responsabilidade de quem governa, de quem conduz. Conforme Matus (1985), planeja quem governa, quem tem a capacidade de decidir, de conduzir. Matus (1985: 36) é tão enfático a este respeito que a terceira das oito considerações apresentadas sobre planejamento situacional em um de seus trabalhos é a de que La planificación es inseparable de la gerencia. Para ele, a única forma para que o planejamento funcione é respondendo às necessidades de quem gerencia. Assim, o planejamento situacional é compreendido como uma forma de organização para a ação, e esta seria sua diferença fundamental em relação ao planejamento tradicional.

No planejamento situacional, a ênfase é colocada no momento da ação e usa a exploração do futuro como recurso para dar raciona- lidade à ação. Cálculo e ação são inseparáveis e recorrentes. Assim, o planejamento é o cálculo que precede e preside a ação. É o cálculo para a decisão a ser tomada hoje (Matus, 1987a). Introduz a noção de que o planejamento está voltado para o presente, já que a única forma de construir o futuro é atuar, e só é possivel agir no presente. Toda ação concreta se faz no presente, para impactar o futuro desejado. Assim, a decisão sobre o que fazer hoje será eficaz ou não para a construção do futuro desejado.

Matus aponta como produto último do plano, o cálculo que precede e preside a ação hoje. Todo cálculo sobre o amanhã aparece como produto intermediário. $O$ presente é o ponto de encontro entre governo e planejamento.

O planejamento situacional se apresenta como cálculo que permite governar em situaçōes de conflito e poder compartilhado e parte da premissa de que não é possível predizer o futuro, mas sim fazer previsões de possibilidades para projetar ações e portanto, ser oportuno e eficaz na ação.

O planejamento situacional aponta o fracasso do planejamento enquanto livro-plano, ou seja, enquanto documento normativo, enquanto um futuro que "deve ser". Como a realidade muda constantemente, é preciso que o planejamento seja a mediação entre o conhecimento e a ação, sendo assim continuamente construído. Em síntese, o planejamento, no enfoque estratégico-situacional, nem se refere ao futuro como coisa essencial nem é apenas um desenho. Este é apenas parte do processo de planejamento.

Cabe ainda explicar o conceito de situação, que se encontra atrelado à compreensão do planejamento em situações de conflito. $O$ planejamento tradicional não considera, além do Estado, outras forças sociais que também planejam. Restringe-se ao planejamento econômico, não incorporando a dimensão política na construção do plano. No enfoque de Matus, o ator está inserido em uma realidade concreta onde existem outros atores, inclusive oponentes, que também planejam. Assim, no enfoque situacional, o planejamento é realizado por atores que têm interesses especifficos, explicações diferentes da realidade, e cada perspectiva estará marcada, condicionada, limitada pela inserção particular de cada ator. Dessa forma, o planeja- 
mento tem que incorporar a perspectiva política como forma de lidar com as resistências de outras forças presentes na realidade. Torna-se imprescindível considerar, além dos recursos econômicos, os recursos de poder existentes para criar viabilidade ao processo de mudança.

\section{OS QUATRO MOMENTOS DO PLANEJAMENTO SITUACIONAL}

O processo de planejamento é concebido por Matus através de quatro momentos fundamentais, os quais, é preciso que fique bem claro, não se confundem com etapas. A idéia de momento indica instância, circunstância ou conjuntura de um processo contínuo que não tem nem início nem fim determinados. Nenhum momento está isolado dos demais. O que $\propto$ corre é um domínio passageiro de um momento sobre os demais ao longo do processo. São eles: o explicativo, o normativo, o estratégico e o tático-operacional.

O momento explicativo é aquele onde se está indagando sobre as oportunidades e problemas que enfrenta o ator que planeja e buscando, antes de tudo, explicar suas origens e causas. Relaciona-se a compreensão do que foi e do que tende a ser a realidade.

O momento normativo corresponde ao desenho de como deve ser a realidade, que, no planejamento tradicional, se confunde com todo o processo de planejamento. Significa a operação que supere os problemas cruciais (chamados de nós críticos), permitindo estabelecer as operaçōes que, em diferentes cenários, levam à mudança da situação inicial em direção à situação objetivo.

O momento estratégico se relaciona à questão da viabilidade e, portanto, aos obstáculos a vencer para aproximar a realidade da situação eleita como objetivo. É nesse momento que deve se dar o cálculo para a superação dos obstáculos que se colocam para a efetivação de mudanças, sejam eles relativos à escassez de recursos econômicos, políticos ou institucionais-organizacionais. Está centrado na identificação do "que pode ser".

O momento tático-operacional é "o fazer" é o momento decisivo do planejamento situacional. Já que o planejamento é concebido como cálculo que precede e preside a ação, as possibilidades ou o alcance do processo de planejamento se darão pela capacidade desse cálculo alterar, conduzir, orientar as açōes presentes. É o momento tático-operacional que articula o planejamento situacional de conjuntura com o planejamento de situações-perspectivas.

\section{O MOMENTO TÁTICO-OPERACIONAL}

Pode ser compreendido a partir de dois movimentos básicos:

- Avaliação da situação na conjuntura — instância de conhecimento;

- Decisão sobre problemas e operações instância de ação.

Os dois apresentam uma relação dialética entre si que concretiza a mediaçāo entre conhecimento e ação. O primeiro - apreciação situacional - conforme Matus (1987b), representa o juizo que permite captar e avaliar a realidade e o desenvolvimento de novos problemas, tendo como perspectiva a análise da direcionalidade do processo. $O$ segundo $-o$ momento das decisōes - volta-se para a resolução dos problemas e operações, constituindose como a via para ajustes entre o plano e a realidade, através das decisões e ações concretas.

O momento tático-operacional combina um processo de avaliação do que se tem feito frente aos efeitos esperados, com uma pré-avaliação dos impactos para conduzir a decisōes que gerem maior aproximação com os objetivos perseguidos.

Dois critérios se apresentam para nortear a condução do dia a dia: a concentração estratégica e a flexibilidade tática. O primeiro implica a concentração sobre os problemas e operaçōes estratégicas, ou seja, tratamentos diferenciados aos vários problemas e operações. $O$ segundo tem por finalidade a comparação entre o que foi simulado e a realidade, tendo em vista melhorar a qualidade dos cálculos seguintes, permitindo uma adaptação flexível entre $o$ plano $e$ as mudanças da realidade.

Conforme Matus, o processo de planejamento supõe a articulação dos momentos explicativo 
(apreciação situacional), normativo (direcionalidade), estratégico (viabilidade) e tático-operacional (cálculo que precede e preside a ação), de modo a constituir um sistema oportuno e eficaz de tomada de decisōes. Essa articulação deve evitar a dissociação entre a ação $\mathrm{e}$ à estratégia, de modo que as restrições do presente não levem a desvios da direcionalidade, nem que a estratégia leve à perda de contato com a ação tática.

Matus (1987b) aponta ainda outros elementos, além do domínio teórico e do cálculo formal, como fundamentais para um sistema de planejamento maduro, que são a experiência, o pragmatismo e a criatividade.

O tipo de problema a ser tratado - processos estruturados ou semi-estruturados - determinará o tipo de avaliação a desenvolver. Quando se enfrentar problemas estruturados, esta ocorrerá através de informação normatizada e auto-explicativa. Quando os problemas tiverem características de processo semi-estruturado, será necessário o juizo situacional deliberativo, que implica enfrentá-los de modo subjetivo e particular.

Segundo Matus, as visões conflitivas no interior do governo impōem, para que uma boa decisão seja tomada, que exista uma convincente argumentação e defesa dos distintos pontos de vista. O autor aponta, entre outros, os seguintes planos onde o conflito pode ocorrer: eficácia econômica versus eficácia política; critérios de curto prazo versus programa de governo e estratégia de longo prazo; tendências ideológicas e éticas contrapostas que incidem sobre a decisão.

Enfim, a mediação entre conhecimento e ação a realizar-se na conjuntura exige uma série de articulações, sendo importante destacar:

1 - Articulação entre o cálculo estratégico e o processo permanente de tomada de decisōes, o que implica conceber o planejamento como processo permanente, onde sempre há um plano sendo feito e, ao mesmo tempo, sempre há um plano para apoiar as decisões.

2 - Articulação entre direção, planejamento e gestão, sob o princípio de que em todos os níveis se dirige e se opera, ainda que com diferentes níveis de complexidade.
Com relação ao sistema de decisões, Matus (1987b) apresenta a visão de múltiplas perspectivas de análise, apresentada originalmente por Allison como uma aproximação a uma teoria situacional da tomada de decisões. Dentre as múltiplas perspectivas, são destacadas a visão política, dominada pelo critério de negociação entre forças distintas; a visão organizativa ou burocrática, dominada por procedimentos institucionais, e também a visão individual, dominada pelas caracteristicas particulares da personalidade de quem toma decisões.

Uma questão a ser enfatizada relaciona-se ao espaço de possibilidades no processo decisório, que será sempre limitado à perspectiva situacional do ator, que estará sempre cega a outras soluçōes que poderiam ser identificadas por outros atores. Desta forma, o dirigente não elege dentre as alternativas existentes, mas sim dentre as que se colocam como tal a partir de sua avaliação situacional.

\section{CONSIDERAÇŌES FINAIS}

O planejamento de matriz cepalina se desenvolveu a partir da preocupação com as racionalidades técnica e, especialmente, econômica na alocação de recursos, atrelando-se à compreensão do planejamento como instrumento para acelerar, dar velocidade ao processo de desenvolvimento (Matus, 1972).

O planejamento era pensado de modo independente da administração. A administração era "o depois", a simples implementação do que foi planejado.

No campo da administração, as formulações teóricas partiram da preocupação com o micro, com a organização - especialmente a empresa privada, com o processo de trabalho e, posteriormente, com o processo administrativo, onde o planejamento aparece como uma entre as suas demais funções básicas (Terry, 1967).

As reflexōes mais recentes, que procuram uma saida para a crise de eficácia tanto na área de planejamento quanto na de administração, apontam de imediato, como ponto comum, a identificação da realidade como complexa e mutante e do elemento político e de poder como recurso crítico a ser considerado.

Matus (1982) não só incorpora as dimensões 
acima destacadas, como também nos apresenta uma concepção mais holística da realidade social e da produção de conhecimentos cientifi$\cos$, de modo a existir uma integração entre economia, política, gerência, teoria da linguagem e outros campos.

Outro aspecto importante relaciona-se à incorporação do conhecimento intuitivo, sensorial, como forma de lidar com circunstâncias onde a previsão não é possível. Esta abordagem significa um avanço com relação ao modelo positivista de ciência. $\mathrm{Na}$ administração, vem sendo destacado o papel de elementos intuitivos ou ológicos presentes no processo decisório (Motta, 1988).

Um último comentário diz respeito ao conceito de situação, que aponta a singularidade da explicação de cada ator, que, segundo a sua inserção, dará significados, interpretaçôes particulares à realidade. Dessa forma, a realidade é concebida como sendo sempre construída, produzida, e não como um dado a ser incorporado.

\section{RESUMO}

\section{AZEVEDO, C. da S. Planejamento e}

Gerência no Enfoque Estratégico-

Situacional de Carlos Matus. Cad. Saúde

Públ., Rio de Janeiro, 8 (2): 129-133, abr/jun, 1992.

Este trabalho pretende abordar a concepção de planejamento e sua articulação com a gerência, presente no enfoque estratégico situacional de Carlos Matus.

$O$ interesse pela articulação

planejamento/gerência se apresenta a partir de reflexões sobre a produção teórica tanto na área de planejamento (em especial planejamento em saúde) como na de administração/gerência, que têm se desenvolvido como campos de conhecimento distintos, mas que, na atualidade, já indicam interseções e indícios de diálogo mais explícito.

As contribuições advindas do pensamento estratégico-situacional de Matus apontam possibilidades de articulação entre as perspectivas oriundas destes dois campos. Inicialmente, serão feitas algumas rápidas considerações sobre os impasses e perspectivas da administração hoje, especialmente no setor público latinoamericano, a fim de possibilitar a identificação do campo de problemas e preocupações que articulam a administração ao planejamento.

Dado o objeto do trabalho, teremos como eixo as concepções de planejamento e gerência presentes em Matus, enfocando também os chamados Momentos do Planejamento Situacional, com ênfase no tático-operacional, que trata do processo de tomada de decisões - questão central para a gerência.

Palavras-Chave: Tomada de Decisão; Situação; Conhecimento; Cálculo; Ação

\section{REFERÊNCIAS BIBLIOGRÁFICAS}

KLIKISBERG, B., 1990. A gerência na década de 90. Revista de Administração Pública, 22: 59-85.

MATUS, C., 1972. Estratégia y Plan. Santiago: Editorial Universitária. 1982. Política y Plan. Caracas: Publicaciones Iveplan. 1985. Planificacion, Liberdad y Conflito. Caracas: Ediciones Iveplan. 1987a. Adios, Señor Presidente. Caracas: Editorial Pomaire. 1987b. Politica, Planificación y Gobierno. Washington: Borrador.

MOTTA, P. R., 1988. Razão e Intuição: Recuperando o ilógico na teoria da decisão gerencial. Revista de Administração Pública, 23: 77-94.

RIVERA, J. U. (Coord.), 1989. Planejamento Programação em Saúde - um enfoque estratégico. Rio de Janeiro: Cortez/Abrasco.

TERRY, G., 1967. Princípios de Administración. México: Companhia Editorial Continental. 